\title{
Modelos literarios en el episodio de las abejas en Babiloníacas de Jámblico (Phot., Bibl. XCIV 3-4)*
}

\author{
Míriam Librán Moreno \\ Universidad de Extremadura \\ mlibmor@unex.es \\ ORCID iD: https://orcid.org/0000-0003-2632-8947
}
Literary Models for the Episode of the Bees in Iamblichus's Babylonian Stories (Phot., Bibl. XCIV 3-4)

\begin{abstract}
El presente artículo se propone estudiar dos de los modelos literarios que ayudaron a inspirar el episodio de las abejas en Babiloníacas de Jámblico (Phot., Bibl. XCIV 3-4): X., An. IV 8.20-21, que narra el envenenamiento de los compañeros de Jenofonte por culpa de la miel tóxica, y un cuento popular del que han quedado restos independientemente en Antonino Liberal (XIX 1-3), Conón (XXXV) y Eliano (NA XVII 45), que relata el ataque de unas abejas sagradas que tienen su colmena en una caverna contra quienes se llevan su miel. Jámblico mezcla modelos literarios para adaptarlos a sus fines creativos.
\end{abstract}

Palabras clave: Jámblico el novelista; Babiloníacas; Jenofonte; cuento popular; abejas.
This paper studies two literary models that served as inspiration for the episode of the bees in Iamblichus's Babylonian Stories (Phot., Bibl. XCIV 3-4): X., An. IV 8.20-21, which relates the Greek soldiers' poisoning after eating toxic honey, and a folktake independently attested by Ant. Lib. XIX 1-3, Cono XXXV, and Ael., NA XVII 45, dealing with the assault carried out against honey thieves by sacred bees nesting in a cave. Iamblichus mixes both literary models to suit his creative purpose.

Key words: Iamblichus the novelist; Babylonian Stories; Xenophon; folktale; bees.

Cómo citar este artículo / Citation: Librán Moreno, Míriam (2021): «Modelos literarios en el episodio de las abejas en Babiloníacas de Jámblico (Phot., Bibl. XCIV 3-4)», Emerita 89 (1), pp. 27-47.

* Este trabajo ha sido elaborado en el marco del proyecto de investigación FFI201455244-P, financiado por el Ministerio de Economía y Competitividad español. Agradezco a los revisores anónimos de Emerita sus valiosas críticas y sugerencias.

Copyright: (C) 2021 CSIC. Este es un artículo de acceso abierto distribuido bajo los términos de la licencia de uso y distribución Creative Commons Reconocimiento 4.0 Internacional (CC BY 4.0). 


\section{El episodio de las abejas en BabiloníaCAS de JÁmblico}

Babiloníacas es una larga y compleja novela de amor y aventuras escrita por Jámblico entre el 166 y el 180 d. C. que no se ha transmitido íntegra. Conservamos de ella unos cien fragmentos (principalmente en la $S u d a$ ) y nueve excerpta de varia extensión, amén de un resumen de su argumento de bastante amplitud a cargo del patriarca Focio (Bibl. XCIV) ${ }^{1}$. La novela, verosímilmente bastante innovadora por lo que cabe colegir de sus restos, era pródiga en peripecias complicadas, truculentas y maravillosas encuadradas en un marco oriental y exótico ${ }^{2}$. Esta escabrosidad, aun así, está puesta al servicio de la oíkovouía literaria de la novela, por lo que no se puede interpretar como mero sensacionalismo ${ }^{3}$.

Uno de esos episodios a medio camino entre lo maravilloso y lo pavoroso narra el encuentro de unas abejas letales con los protagonistas, Ródanes y Sinónide, y con los soldados que los persiguen ${ }^{4}$. Ambos jóvenes, huyendo del ejército encabezado por el eunuco Damas (que tiene encomendado capturarlos para entregarlos a su enemigo, el rey Garmo), se refugian en una caverna de doble entrada (Iambl. fr. 10 B. $=11$ H.). Los soldados los persiguen hasta el interior y allí se topan con un enjambre de abejas que han hecho su colmena en la roca de la cueva (Iambl. fr. 13 B. $=15$ H.). Las abejas se revuelven contra los intrusos y se lanzan contra ellos. Es preciso citar el resumen del episodio hecho por Focio (Bibl. XCIV 3-4) por extenso:

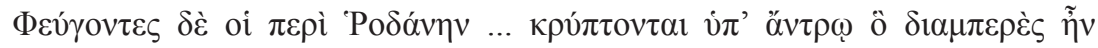

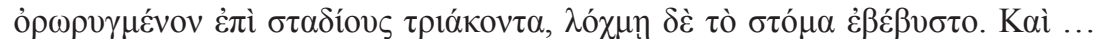

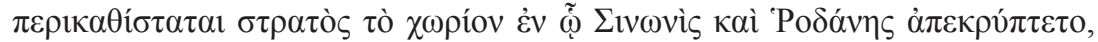

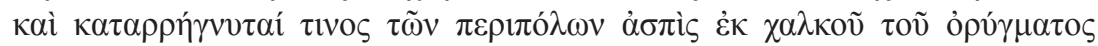

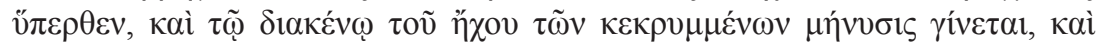

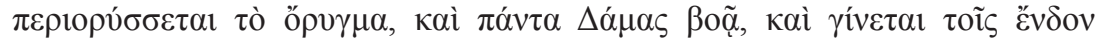

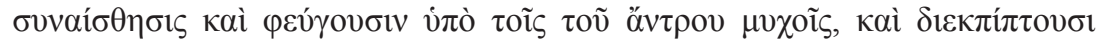

${ }^{1}$ Kroll 1914, coll. 640-641; Barbero 2015, pp. 1, 7-33. Las dos principales ediciones modernas de Babiloníacas son las de Habrich 1960 y Barbero 2015. Cito el texto de este último. Un resumen del complicado argumento se puede ver en Rojas 2016, pp. 41-42.

${ }^{2}$ Holzberg 1986, pp. 86-87, Barbero 2015, p. 2, Kanavou 2019, pp. 109-110. Sobre el aspecto literario de la obra todavía es imprescindible consultar a Schneider-Menzel 1948.

${ }^{3}$ Kroll 1914, coll. 641-642.

${ }^{4}$ Kanavou 2019, p. 120. 


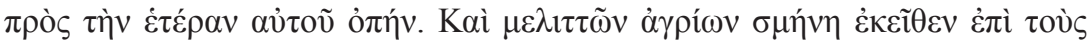

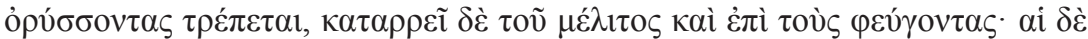

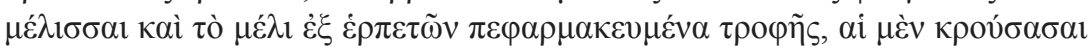

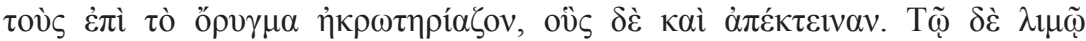

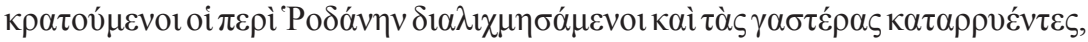

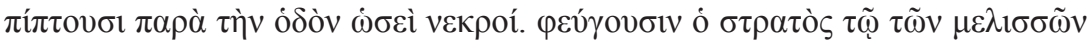

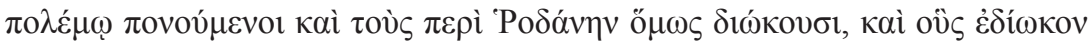

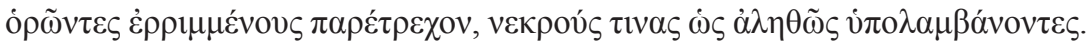

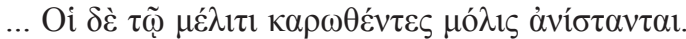

En su huida Ródanes y su compañera se ocultan en una cueva que estaba horadada de parte a parte en una longitud de 30 estadios; la maleza había taponado la entrada. ... El ejército rodea el lugar en el que Sinónide y Ródanes se han escondido, y se cae y se hace añicos por encima de la cueva el escudo de bronce de uno de los guardianes, y por causa del sonido hueco del eco se revela la localización de los escondidos. Empiezan a excavar alrededor de la oquedad, Damas da todo tipo de gritos, y los que están dentro se enteran y huyen a la parte más interior de la caverna y se abren paso hasta salir por la otra entrada. Desde allí un enjambre de abejas salvajes se vuelve contra los que estaban junto al túnel y destila miel también sobre los que huyen. Pero las abejas y la miel, como estaban emponzoñadas por el alimento de las serpientes, con sus aguijonazos mutilaban a los que estaban excavando, y a otros incluso los mataron. Ródanes y su compañera, vencidos por el hambre, se pusieron a lamer la miel que les había caído encima. Sufren un cólico de estómago y caen al suelo junto al camino como si fueran cadáveres. El ejército, agotado tras la guerra de las abejas, se da a la fuga, pero aun así continúa persiguiendo a Ródanes y su compañera. Cuando ven que los que perseguían estaban tirados en el suelo, los pasaron de largo, pensando que de verdad eran unos cadáveres ... Pero ellos ( $s c$. Ródanes y Sinónide), tras haber caído en coma por culpa de la miel, se levantan con dificultad ${ }^{5}$.

${ }^{5}$ El resumen de Focio no parece seguir el orden cronológico estricto de la narración. Esta es la reconstrucción de la secuencia de acontecimientos hecha por Borgogno 1975, pp. 120, 122: los hombres de Damas rodean el lugar bajo el cual está excavada la caverna. Dentro de la caverna, Sinónide se corta las trenzas para poder sacar agua con ellas. Los hombres de Damas se dan cuenta de que se encuentran sobre una oquedad por el eco provocado por la caída de un escudo de bronce. Ante esto, Damas grita y sus hombres se ponen a excavar la oquedad. Sinónide y Ródanes se aperciben de que los han descubierto y huyen al interior de la caverna en dirección a la segunda entrada. Damas, gracias al trabajo de sus hombres, penetra en la cueva. Sinónide y Ródanes, ya fuera de la cavidad, se manchan con la miel destilada por un panal habitado por 
Además del resumen de Focio, varios fragmentos de Babiloníacas de Jámblico (frs. 10-15 B.) conservados por la Suda aluden a este episodio, de los que cito dos:

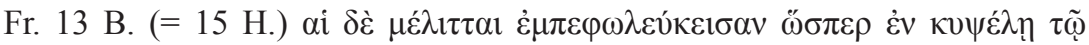

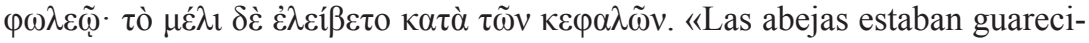
das en la cueva como si estuvieran en una colmena: y su miel les caía gota a gota sobre la cabeza».

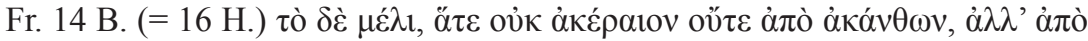

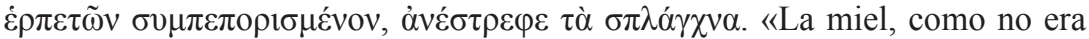
sin mezcla ni estaba hecha de acanto ${ }^{6}$, sino procurada a partir de las serpientes, les revolvía las entrañas».

El propósito del presente artículo es doble: por un lado, proponer los modelos literarios de los que pudo haberse valido Jámblico a la hora de crear tan sorprendente episodio, y por el otro indagar en el uso literario que pudo haberles dado.

\section{Dos posibles modelos literarios en El ePISOdIO DE LAS ABEJAS EN BABILONÍACAS}

Según la nota biográfica conservada en un escolio al margen del ms. A de Biblioteca de Focio (f. 72r), Jámblico, cuya lengua nativa era el sirio, se aplicó a ejercitarse y dominar la lengua griega con vistas a convertirse en un buen rétor ( $\tau \grave{v} v$

abejas salvajes, situado en un recodo sobre la segunda salida de la cueva. Las abejas salen de la colmena y se lanzan contra los soldados que están excavando en la cueva. Los hombres de Damas resultan diezmados por los aguijones de las abejas y su miel venenosa. Sinónide y Ródanes prosiguen su huida pero, sintiendo hambre, lamen la miel que los ha salpicado, de resultas de lo cual caen al borde del camino como muertos. Damas, dentro de la cueva, halla la trenza que se ha cortado Sinónide. A la salida de la caverna Damas se encuentra con los soldados que han salvado su vida al huir de las abejas. Los hombres de Damas continúan su persecución y se topan con Ródanes y Sinónide tumbados a lo largo del camino. Al creerlos muertos, pasan de largo. Sinónide y Ródanes acaban despertándose con dificultad y reemprenden la huida en dirección contraria.

${ }^{6} \mathrm{El}$ acanto (acanthus mollis) era una de las plantas favoritas de las abejas (Colum. IX 4.4). Sobre la miel tóxica de Asia Menor, elaborada principalmente a base de azalea y boj, véase Schneider-Menzel 1948, p. 59 n.13; Stephens y Winkler 1995, p. 191 n. 21. 


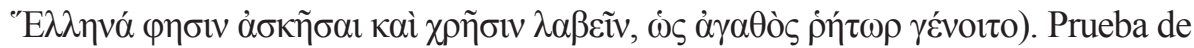

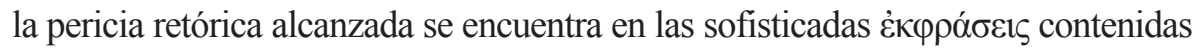
en la novela, pródigas en ecos literarios ${ }^{7}$. Efectivamente, Jámblico, como otros novelistas influidos por la Segunda Sofística, era un autor literariamente muy sofisticado ${ }^{8}$ : lo que se ha conservado de su obra permite apreciar su $\pi \circ \lambda v \mu \alpha \theta i ́ \alpha$, en forma de alusiones intertextuales a distintos autores de diferentes géneros ${ }^{9}$. Por ello, propongo que en el episodio de las abejas en Babiloníacas podemos encontrar una combinación armónica de al menos dos modelos literarios principales, que ayudaron a dar forma literaria a un episodio sumamente original.

En cuanto a la descripción de la caverna en la que viven las abejas, Jámblico refleja la tópica descripción de la gruta de las ninfas en Hom., Od. XIII 102-109, con la que tiene en común el hecho de que están situadas cerca de cubiertas vegetales (la maleza o espesura en Iambl. fr. 10 B. ( = 11 H.), los acebuches en Hom., Od. XIII 102-103) ${ }^{10}$, en ambas custodian su miel las abejas (Iambl. fr. 13 B. (= 15 H.), Hom., Od. XIII 106), en ambas hay fuentes que manan agua (Phot., Bibl. XCIV 4, Hom., Od. XIII 109) y ambas cuentan con dos entradas (Iambl. fr. 10 B. $=11$ H., Hom., Od. XIII 109). Si bien Homero está presente de forma fundamental en los novelistas, sobre todo en Caritón y en Heliodoro, la descripción de la caverna en Jámblico respondería más bien a un tópico literario y retórico bien divulgado y conocido en la época ${ }^{11}$, utilizado también en la novela ${ }^{12}$, cuyo origen se remonta a Homero, más que a una imitación directa de este ${ }^{13}$. Por otra parte, la idea de que las abejas construyen su panal en una gruta, no en el hueco de un árbol, aparece también en Hom., Il. II 87-88. El retrato de las abejas como soldados que defienden sus panales y sus crías del asalto de los hombres que buscan su miel ya se encuentra en un

${ }^{7}$ Di Gregorio 1963, p. 405; Holzberg 1986, pp. 84, 86.

${ }^{8}$ Holzberg 1986, p. 84; Connors 2018, pp. 40-41.

${ }^{9}$ Gärtner 2010, p. 257.

${ }^{10}$ Este es, en mi opinión, el origen del arbusto que tapa una de las entradas de la caverna en Jámblico. Su función literaria parece clara: los soldados no deben darse cuenta de la existencia de la entrada hasta que la descubren fortuitamente gracias al ruido provocado por la caída del escudo (Phot., Bibl. XCIV 3). Para ello, la entrada debe estar tapada. Puede verse otra explicación en Connors 2018, p. 45.

${ }^{11}$ Beck 1982, pp. 531-532.

12 Borgogno 1975, p. 117; Crespo 1982, p. 400 n. 22.

13 Compárese con las conclusiones a las que llega Sanz Morales 2020 sobre las fuentes del fr. 2 B. de Babiloníacas. 
conocido símil de Homero (Il. XII 167-170), pero una vez más la inspiración verosímilmente no es directa, ya que una y otra son ideas comunes.

A mi juicio, Jámblico ha contaminado dos modelos literarios principales en el episodio de las abejas, que se reflejan en los dos acontecimientos fundamentales de este: (1) muerte aparente tras la ingestión de miel tóxica; (2) asalto de unas abejas sagradas. Dichos modelos literarios son un texto historiográfico (véase apartado 1) y un cuento popular (véase apartado 2) ${ }^{14}$.

\section{Muerte aparente tras consumir miel venenosa: X., An. IV 8.20-21}

Hay numerosas anécdotas en la literatura grecolatina sobre un tipo de miel, llamado por Plinio (Nat. XXI 13 § 77) meli maenomenon, que las abejas elaboraban a partir de plantas tóxicas como la azalea o el boj en el Cáucaso y Asia Menor, que causaba locura transitoria, desmayos y gastroenteritis a los seres humanos e incluso la muerte a los animales de menor tamaño ${ }^{15}$. Hay dos anécdotas, narradas por X., An. IV 8.20-21 y Str. XII 3.18, que demuestran dramáticamente las consecuencias para los seres humanos de la ingesta de miel tóxica. A mi juicio, el episodio de las abejas en Jámblico no tiene relación con el texto de Estrabón ${ }^{16}$, sino que debemos fijarnos en el pasaje de Jenofonte, en el que describe la intoxicación por miel sufrida por sus compañeros:

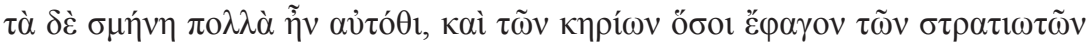

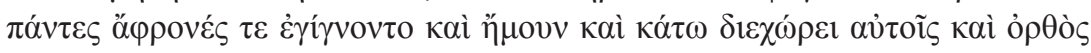

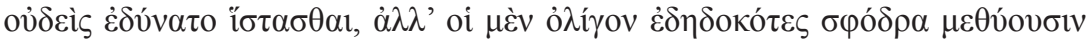

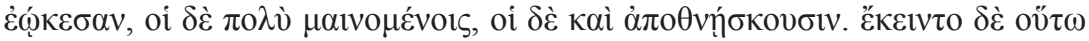

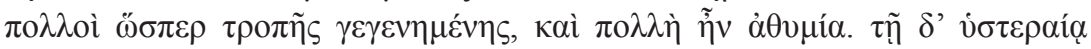

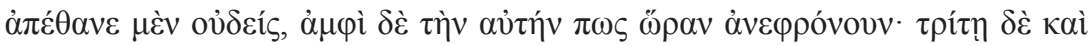

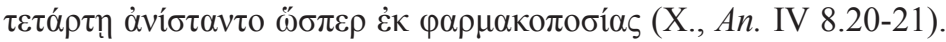

14 Ambos textos son aducidos, aunque sin analizar, en conexión con el fondo de narración popular en el episodio de las abejas de Babiloníacas en Librán y Sanz 2019, pp. 212-213.

15 Mayor 1995, pp. 33-37.

16 En esto discrepo de Connors 2018, p. 44. En el pasaje de Estrabón, los Heptacometas, un pueblo de la Cólquide, tendió una trampa a los soldados de Pompeyo poniendo en su camino crateras de vino mezclado con miel venenosa. Los soldados bebieron de las crateras y cayeron en coma al suelo; los nativos aprovecharon para matarlos con facilidad. Como se ve, los únicos puntos de contacto con la narración de Babiloníacas serían la miel tóxica y la presencia de soldados. 
Había allí un gran número de enjambres, y cuantos soldados probaron la miel perdieron la cabeza y empezaron a vomitar y a tener diarrea; ninguno de ellos era capaz de tenerse en pie, sino que los que habían comido una cantidad pequeña se parecían a alguien que tuviera una fuerte borrachera, mientras que los que habían comido mucha unos parecían enloquecidos y otros muertos. Yacían así en gran número como si se hubiera producido una derrota, y cundió el desánimo. Pero al día siguiente nadie había muerto, y en torno a la misma hora, más o menos, empezaron a recuperar la consciencia. Al tercer y cuarto día se levantaron, como si se hubieran recuperado de un envenenamiento.

Cabrá observar que hay claros paralelos de situación entre los pasajes de Jenofonte y Jámblico: un grupo de personas se topa con unos panales con miel, sienten hambre, comen de la miel, que es venenosa, sin ser conscientes de su carácter tóxico y resultan envenenados. Como consecuencia, los afectados sufren una gran diarrea, se desvanecen rápidamente y son dados por muertos. Sin embargo, al cabo de un tiempo los intoxicados recobran poco a poco la consciencia, como si se recuperaran de un envenenamiento, y continúan su marcha sin secuelas ${ }^{17}$.

A dichos paralelos de contenido y situación hay que sumar algunos ecos verbales, lógicamente no literales, ya que solo tenemos el resumen de Focio para comparar ${ }^{18}$ :

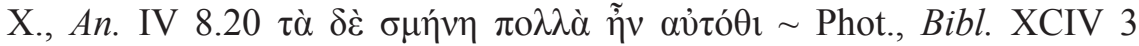

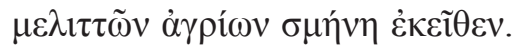

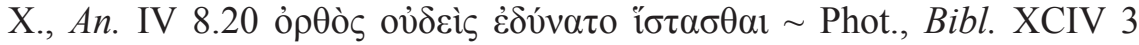

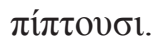

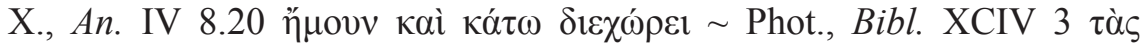

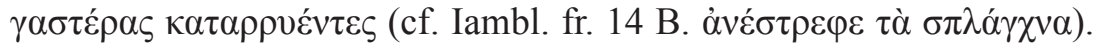

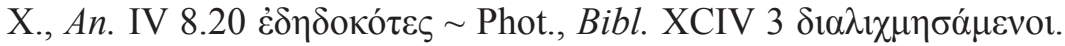

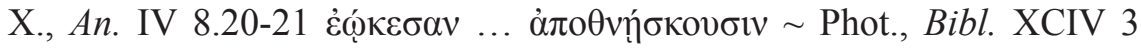

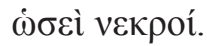

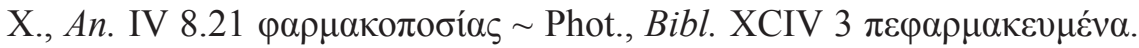

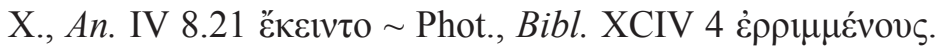

${ }^{17}$ Librán y Sanz 2019, p. 213.

${ }^{18}$ La comparación entre el epítome de Focio y los fragmentos conservados de Babiloníacas apunta a que el Patriarca resumió de forma bastante fiel el texto de Jámblico (Borgogno 1975, p. 121), pero evidentemente son esperables cambios y algún grado de paráfrasis en el vocabulario. 


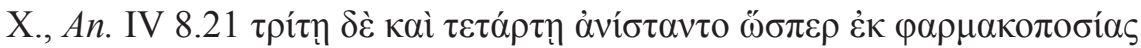

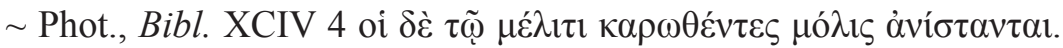

Como se sabe, Jenofonte es una influencia muy relevante en la novela griega de amor y aventuras, no solo por la Ciropedia, sino también por la Anábasis y otras obras menores de este autor ${ }^{19}$. Otro tanto ocurre en Babiloníacas, de lo que es suficiente testimonio los abundantes ecos literarios de Jenofonte que se pueden encontrar sin dificultad, por ejemplo, en el fr. 2 B. ( = $1 \mathrm{H}$.) de Jámblico ${ }^{20}$. Por ello, no debería causar sorpresa encontrar en el episodio de las abejas el empleo de un hipotexto jenofonteo.

\section{El ataque de las abejas sagradas: un cuento popular atestiguado en} Ant. Lib. XIX 1-3, Cono XXXV y Ael., NA XVII 45

Hasta ahora he examinado el modelo literario que pudo inspirar el envenenamiento con miel tóxica y posterior recuperación de Ródanes y Sinónide. Me centro ahora en el segundo acontecimiento principal dentro de dicho episodio, la batalla de las abejas contra los soldados de Damas. A mi juicio, podría proceder de un cuento popular o maravilloso (folktale, Märchen) ${ }^{21}$ sobre el ataque de unas abejas sobrenaturales o especiales que han fabricado su colmena en una cueva sagrada, del que parecen haber quedado restos literarios de forma independiente en Eliano (NA XVII 45), Antonino Liberal (XIX 1-3) $)^{22}$, así como en Conón (XXXV) ${ }^{23}$.

19 Holzberg 1986, pp. 15, 42, 46-47; Ruiz Montero 2006, p. 48; Bowie 2017, pp. 406-409.

${ }^{20}$ Naechster 1908, pp. 57-59; Bowie 2017, p. 408; Sanz Morales 2020, pp. 512-515. Jámblico parece aficionado a la historiografía: aparte de Jenofonte, con frecuencia utiliza como modelo a Heródoto (Schneider-Menzel 1948, p. 84). Véase además infra n. 46.

${ }^{21}$ Anderson (2000, p. 1) ofrece una definición breve del cuento popular (folktale, Märchen): «short, imaginative, traditional tales with a high moral and magical content».

${ }^{22}$ Cook 1895, p. 2 («This narrative [sc. de Eliano] ... affords a partial explanation of the legend recorded by Antoninus»); Papathomopoulos 1968, p. 113 n. 11; Celoria 1992, p. 157. La narración de Antonio Liberal se retrotrae a un cuento popular («wirkliche Volkssage», Walter ap. Lamer 1924, coll. 512-513) documentado iconográficamente ya en el s. VI a. C. en un ánfora de figuras negras custodiada en el British Museum (Catalogue of Greek Vases in the British Museum B 177, inv. 1847, 0716.1). Véase además Papathomopoulos 1968, p. 113 n. 12; Mitchell 2009, pp. 148-149.

${ }^{23}$ «A more folky tale ... with similar elements: cave, bees, honey, theft (of gold)», Celoria 1992, p. 156. 
Cabe recordar que la reelaboración literaria de cuentos populares en $\mathrm{Ba}$ biloníacas, así como de motivos registrados en estos, está bien documenta$\mathrm{da}^{24}$. Muchas veces unos y otros son de procedencia oriental ${ }^{25}$, lo cual es congruente con la noticia que transmite el propio Jámblico sobre el origen del argumento de su novela (sch. mg. A Phot., Bibl. $\tilde{\omega} v$ [sc. B $\alpha \beta v \lambda \omega v i ́ \omega v$

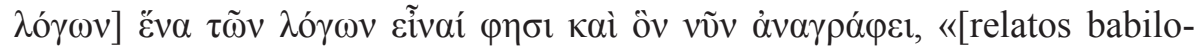
nios]... de los cuales dice que es uno también el que ahora pone por escrito») ${ }^{26}$. En el episodio de las abejas de Babiloníacas se documentan en concreto varios motivos procedentes del índice de motivos folclóricos de Thompson 1955-1958 ${ }^{27}$. Son los siguientes.

En cuanto a la derrota y fuga de los soldados de Damas por culpa de las $\operatorname{abejas}^{28}$ :

B481.3 Helpful bee.

B524.2.1 Helpful bees (hornets) sting opposing army.

K2351.2 Bees thrown into redoubt drive out enemies.

Q597.3 Bees sting honey-thieves.

En cuanto a unas abejas y una miel de procedencia subterránea cuya ingestión resulta peligrosa o letal:

C211.2 Tabu: eating in lower world.

D1037 Magic honey.

F167.1.3.1 Bees in otherworld.

${ }^{24}$ Rohde 1876, p. 379; Braccini 2015, pp. x-xii; Librán 2019, pp. 291-306. Véase además Ruiz Montero 2006, pp. 37-39 sobre el análisis morfológico del esquema narrativo de las novelas idealistas partiendo de la Morfología del cuento de V. I. Propp.

${ }_{25}$ Rohde 1876, p. 367, n. 2; Librán 2019, pp. 298-299, 304.

${ }^{26}$ Dowden 2018, pp. 154-160. Anderson (2004, pp. 109-118) aduce varios paralelos narrativos en favor de la tesis de que el argumento de Babiloníacas refleja una versión persa de la leyenda de Tristán.

27 Dichos motivos son, en definición de Hansen 2002, p. 30, n. 19, «small narrative ideas that in combination make up whole stories».

${ }^{28}$ Véase Librán y Sanz 2019, p. 212. 
Evidentemente, en el caso de Jámblico, que tiende a racionalizar los sucesos maravillosos que narra en su novela ${ }^{29}$, el inframundo se ve sustituido por la caverna subterránea, mucho más realista.

Pasemos al examen del cuento popular propuesto en sí. Según Eliano ( $N A$ XVII 45), Anténor de Creta (463 F 1 FGrH), del s. II a.C., recogió en su historia de Creta una guerra entre unas abejas especiales y los habitantes de la ciudad cretense de Rauco:

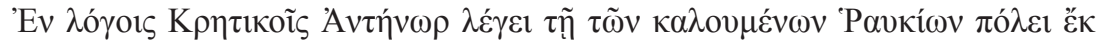

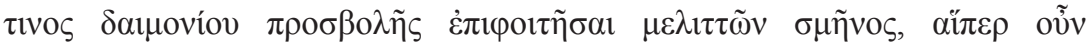

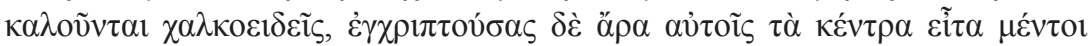

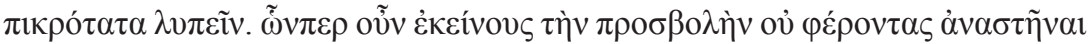

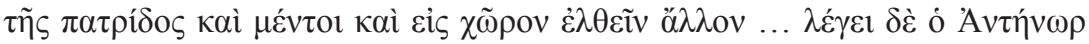

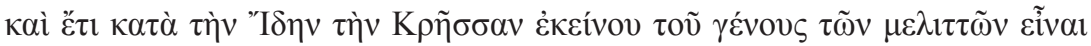

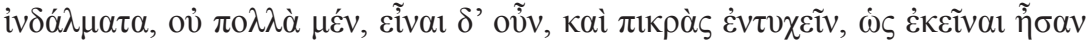
(Ael., NA XVII 45).

Anténor, en su historia sobre Creta, dice que por causa de cierto ataque divino invadió la ciudad de los llamados Raucios un enjambre de abejas, a las que daban el nombre de 'de aspecto de bronce'. Pero después las abejas, persiguiéndolos con sus aguijones, les causaban un daño muy intenso. Al no ser capaces de aguantar el embate de estas, tuvieron que emigrar de su patria y marcharse a otra tierra ... y dice Anténor que incluso todavía hoy hay abejas semejantes a las de aquella especie en el Ida de Creta, no muchas, pero hay, y encontrarse con ellas es doloroso, como lo era con aquellas.

Como puede verse, la breve noticia de Eliano tiene en común con el episodio de Jámblico algunos elementos de contenido: unas abejas asaltan a un gran grupo de personas, a las que causan un grave dolor con sus aguijones

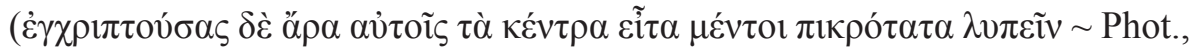

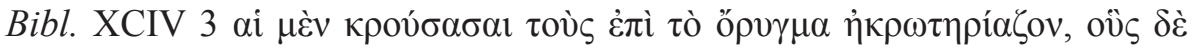
$\kappa \alpha \grave{\alpha} \pi \dot{\varepsilon} \kappa \tau \varepsilon i v \alpha v)$. Los que sufren el asalto tienen que darse a la fuga para

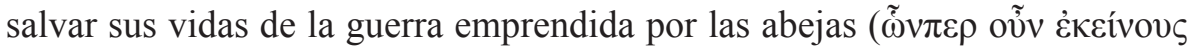

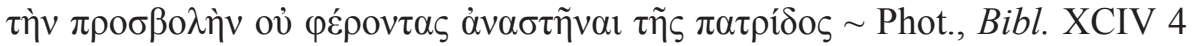

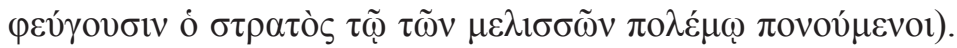

\footnotetext{
${ }^{29}$ Schneider-Menzel 1948, p. 88. Véase además infra apartado III.
} 
Trataré Ant. Lib. XIX 1-3 y Cono XXXV al mismo tiempo y separadamente del pasaje de Eliano, ya que ambos atestiguan una versión muy similar del cuento popular sobre las abejas sagradas de $\mathrm{Creta}^{30}$, con diferencias con respecto a Eliano.

En el caso de Antonino Liberal, en una narración tomada del libro II de la Ornitogonía de Beo, la acción transcurre en una cueva sagrada de Creta, donde asimismo habitan unas abejas igualmente sagradas. Hasta el sitio en el que ellas custodian sus panales se adentran cuatro hombres, que desean hacerse con la miel de las abejas. Los cuatro ladrones casi resultan muertos como consecuencia de su atrevimiento al entrar en la cueva para robar la miel de los insectos ${ }^{31}$ :

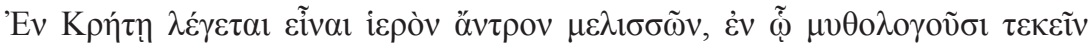

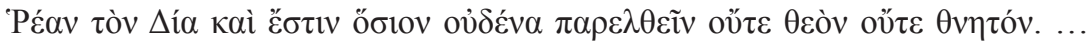

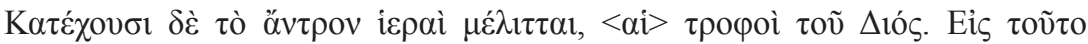

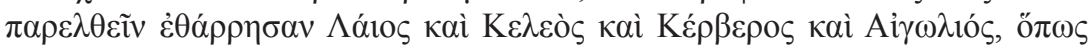

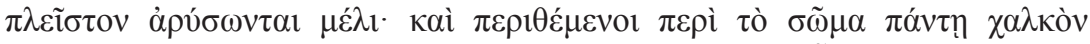

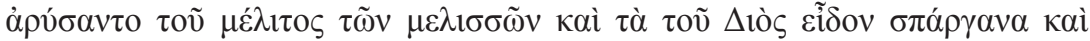

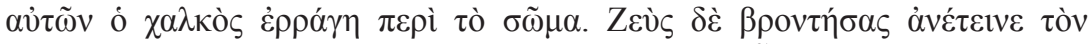

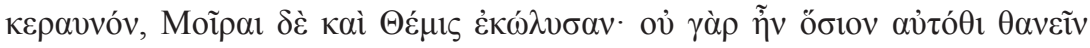

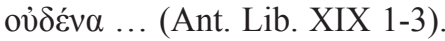

Dicen que en Creta hay una gruta sagrada de abejas, en la que cuentan que Rea dio a luz a Zeus, y que es ley divina que nadie entre, ni dios ni mortal ... Habitan en la cueva unas abejas sagradas, las nodrizas de Zeus. Layo, Celeo, Cérbero y Egolio tuvieron el atrevimiento de entrar para extraer miel en la mayor cantidad posible. Se recubrieron todo el cuerpo con bronce y extrajeron la miel de las abejas. Vieron los pañales de Zeus y la armadura de bronce se les rompió en torno al cuerpo. Zeus, tronando, blandió el rayo, pero las Moiras y Temis lo impidieron: pues no era lícito que muriera nadie allí mismo ...

En el caso de Cono $\mathrm{XXXV}^{32}$, dos pastores encuentran una profunda cueva donde residía un enjambre de abejas y uno de ellos decide descolgarse hasta

${ }_{30}$ Celoria 1992, p. 156; Brown 2002, p. 245. De hecho, el cuento popular reelaborado por Cono XXXV tiene su reflejo en varios elementos de la aventura de Ródanes y Sinónide en la cueva, no solo en el detalle de las abejas y la miel. Véase Librán y Sanz 2019, p. 213.

${ }^{31}$ No es el propósito del presente artículo apreciar el valor mítico o religioso de la historia. Véase al respecto e. g. Celoria 1992, p. 156.

32 Celoria 1992, p. 156; Brown 2002, p. 245. 
su interior para robar la miel. Pese a numerosas desventuras y traiciones, este pastor logra salir milagrosamente vivo de la caverna, tras causarse varias mutilaciones a sí mismo, transportado por varios buitres:

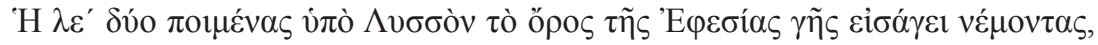

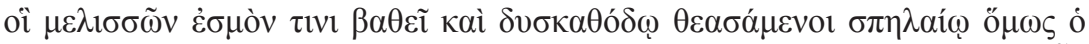

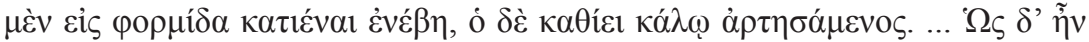

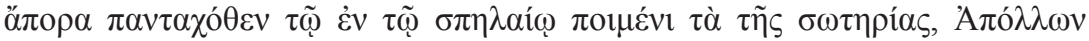

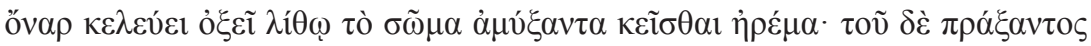

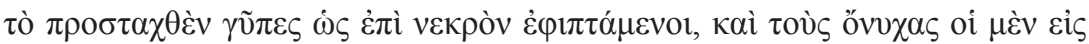

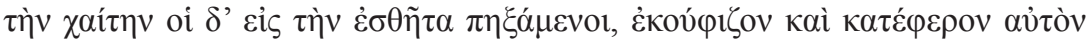

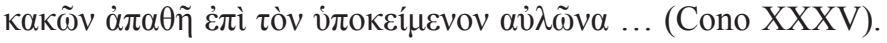

La narración 35 presenta a dos pastores que apacentaban su rebaño a los pies del monte Liso en Éfeso. Ellos, aunque observaron un enjambre de abejas en una caverna profunda y de difícil acceso, no obstante, uno se metió en un cesto para descender, mientras que el otro lo descolgaba después de suspenderlo con una cuerda ... Como la salvación era completamente imposible para el pastor que estaba en la caverna, Apolo le ordena en sueños que se lacerara el cuerpo con una piedra afilada y después se tumbara en silencio. Cuando el pastor hizo lo ordenado, unos buitres, sobrevolándolo como si fuera un cadáver, tras clavar las garras unos en la cabellera y otros en la ropa del pastor, lo levantaron en el aire y lo transportaron, sin sufrir daño, hasta un desfiladero cercano ...

El relato de Jámblico tiene numerosos elementos de contenido en común con las narraciones de Eliano, Antonino Liberal y Conón, con las diferencias naturales esperables en versiones distintas aun cuando dependan de una misma matriz de cuento popular ${ }^{33}$ :

- La aventura tiene lugar en una caverna en la que habita un enjambre de

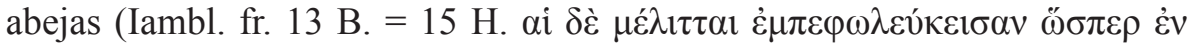

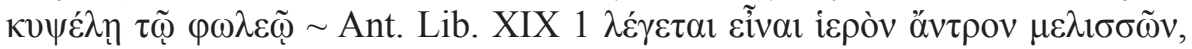

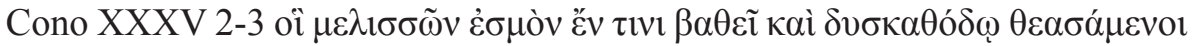
$\sigma \pi \eta \lambda \alpha i ́(\omega)$.

${ }^{33}$ Sobre la existencia de diferencias y variantes en los elementos que forman las versiones de este (o cualquier otro) cuento popular, véase Hansen 2002, pp. 352, 354. Hay que insistir en que no propongo que Jámblico se haya inspirado en Conón, Antonino Liberal o Eliano (en algún caso, es imposible por motivos cronológicos), sino que todos ellos reflejan, de forma independiente, variaciones de un mismo cuento popular. 
- Dichas abejas tienen una naturaleza o carácter especial: tienen aspecto de bronce (Ael., NA XVII $45 \chi \alpha \lambda \kappa o \varepsilon 1 \delta \varepsilon i \varsigma)$ por don de Zeus, son sagradas (Ant. Lib. XIX 1 i $\varepsilon \rho \alpha i$ ) o tóxicas (Phot., Bibl. XCIV $3 \pi \varepsilon \varphi \alpha \rho \mu \alpha \kappa \varepsilon v \mu \varepsilon ́ v \alpha$ ).

- Una o varias personas descienden a la caverna y se apoderan de la miel

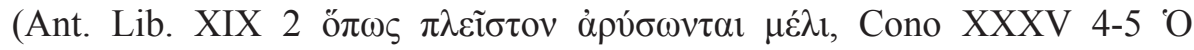

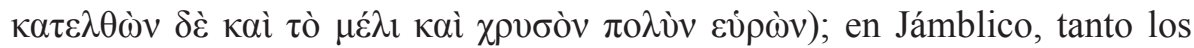
protagonistas como los soldados que están abriéndose paso a la fuerza por la cueva también se encuentran con la miel; al caerles esta gota a gota sobre la

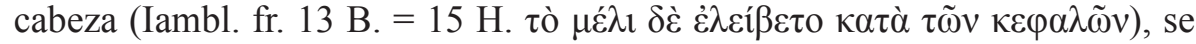

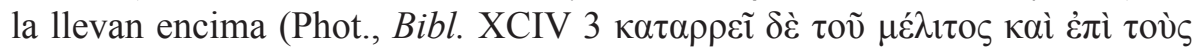

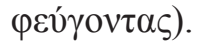

- La armadura de bronce con la que estaban revestidos los ladrones de

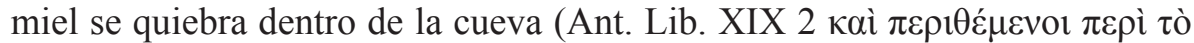

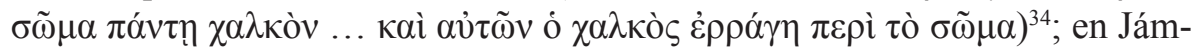
blico se rompe el escudo de bronce de un soldado sobre la entrada de la ca-

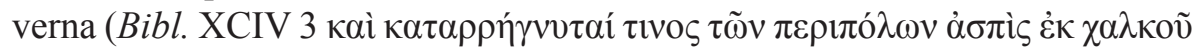

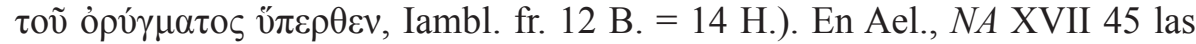
abejas son broncíneas ( $\chi \alpha \lambda \kappa o \varepsilon 1 \delta \varepsilon i \tilde{\varsigma})$.

- Quienes se topan con las abejas en la cueva o en el territorio de estas sufren su ataque furibundo de forma tan intensa que no son capaces de soportar el dolor de sus aguijones y deben huir y cederles el terreno a los insectos (Ael.,

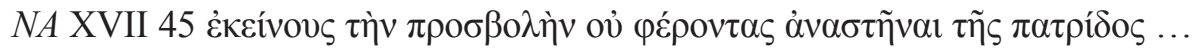

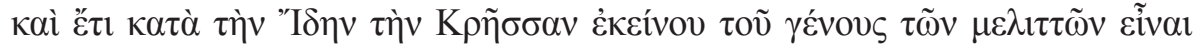

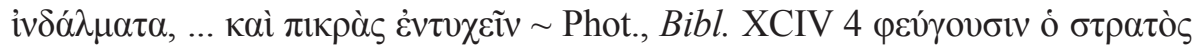

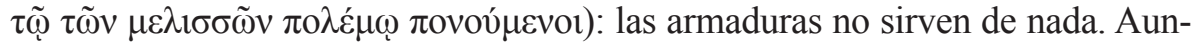
que no ha quedado reflejo textual, la pintura vascular que ilustra la leyenda popular relatada por Antonino Liberal retrata también a los cuatro ladrones de miel desnudos y con evidentes muestras de dolor ante los aguijonazos de las abejas, mientras que al menos uno de ellos se da a la fuga ${ }^{35}$.

${ }^{34}$ Este artículo no entra en el valor ritual o mitológico del bronce en este episodio, sobre el cual véase e.g. Papathomopoulos 1968, p. 113, n. 11; Celoria 1992, p. 158.

${ }^{35}$ La pintura vascular mencionada supra n. 22, que refleja la leyenda popular relatada por Antonino Liberal, puede verse online: British Museum Collection Database. 1847, 0716.1 $<$ www.britishmuseum.org/collection>, British Museum, accesible en $<$ https://research.britishmuseum.org/research/collection_online/collection_object_details.aspx?objectId=398899\&pag $\mathrm{e}=1 \&$ partId=1\&peoA=97470-3-17\&people $=97470>(27 / 06 / 2020)$. 
- Los fugitivos escapan, tras sufrir mutilaciones ${ }^{36}$, de una muerte segura

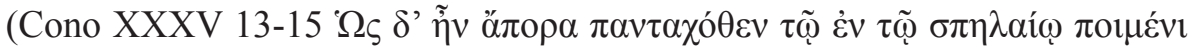

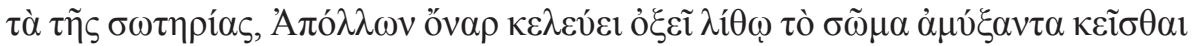

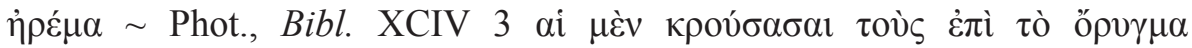

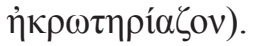

En suma, los rasgos comunes que atestiguan las versiones del cuento popular propuesto, tal y como los reflejan Jámblico, Antonino Liberal, Conón y Eliano, son los siguientes: (1) Algunas personas entran en una gruta sagrada donde unas abejas de naturaleza especial tienen su colmena. (2) Las abejas sagradas guardan su miel en dicha cueva. (3) Los protagonistas se llevan la miel (por robo o involuntariamente). (4) Las abejas atacan (con sus aguijones o con su miel) y provocan gran daño a quienes les quitan la miel o se adentran en su territorio. (5) Las víctimas deben ceder el terreno a las abejas y huir, y escapan a la muerte por poco, tras sufrir mutilaciones. Compárese con la lista de motivos del índice de Thompson 1955-1958 aducidos supra. Dicho cuento popular, por tanto, narraría cómo unas abejas de una naturaleza especial y un temperamento especialmente belicoso repelieron a personas que trataban de robar su miel e hicieron huir a quienes estaban demasiado cerca de su colmena, situada en una gruta sagrada (verosímilmente la cueva en el monte cretense de Ida donde nació Zeus).

Es necesario insistir en que el modelo que subyace en esta parte del episodio de las abejas de Babiloníacas no es, a diferencia de lo que ocurre con el pasaje de Jenofonte citado supra en el apartado 1, un texto literario definido y con autor conocido, sino un cuento popular del que han quedado restos parciales en las versiones literarias independientes de Antonino Liberal, Conón y Eliano. Por su propia naturaleza, si hubiera ecos verbales, serían muy difíciles de detectar.

En definitiva, Babiloníacas alude en numerosas ocasiones a cuentos populares y motivos procedentes de estos, adaptados y remodelados, por supuesto, para ajustarlos a los propósitos literarios del autor. Por ello, no es

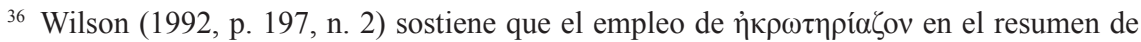
Focio implica que la picadura de las abejas obliga a los soldados a amputarse el miembro herido. Tanto Sevieri (2017, p. 67) como Bianchi y Schiano (2016, p. 1027, n. 9) aceptan esta interpretación. Estos últimos aducen un pasaje de Agatías (II 3.7) para detectar en el uso de

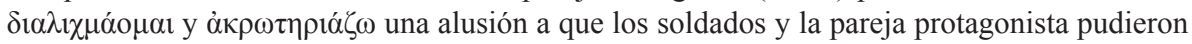
haberse mutilado por enloquecimiento debido a la ingestión de la miel. 
extraño encontrar la influencia de un cuento popular también en el episodio estudiado.

\section{Contaminación DE MOdelos EN BABILONÍACAS}

No es el episodio de las abejas en la gruta el único caso en el que Jámblico combina, para sus propios fines creativos, dos modelos literarios, uno procedente de la historiografía y otro del cuento popular ${ }^{37}$. Está bien documentada la práctica de Jámblico de mezclar y reelaborar modelos literarios en su novela para apuntalar sus objetivos literarios ${ }^{38}$ : baste traer a la memoria el episodio del perro hircano de Ródanes (Phot., Bibl. XCIV 18), en el que se funden, de forma muy creativa e innovadora, alusiones a la leyenda de Erígona y su perra Mera $^{39}$, la historia de Cianipo y Leucónoe ${ }^{40}$ y las desventuras de Píramo y Tisbe ${ }^{41}$. Jámblico no acumula alusiones literarias de forma acrítica o como simple adorno retórico, sino que les asigna una función literaria que sirva a sus propios objetivos creativos, tal como motivar o preparar el terreno para episodios posteriores ${ }^{42}$.

En el caso que nos ocupa, el propósito narrativo de Jámblico al amalgamar estos dos modelos literarios en la aventura de las abejas puede ser doble.

(a) Por un lado, la inserción de un suceso inspirado en un texto historiográfico (envenenamiento por miel tóxica), y por tanto presuntamente veraz, en un cuento popular maravilloso (el ataque de unas peligrosas abejas sagradas) puede obedecer a la tendencia, constatable en otros pasajes de Babiloníacas que relatan sucesos maravillosos o sobrenaturales, a racionalizar de forma más o menos realista la aparición de lo fantástico ${ }^{43}$ : la falsa muerte de Ródanes y Sinónide (el típico Scheintod novelístico) está motivada por la ingestión de una miel tóxica, de origen, no mágico, sino natural, al estar

${ }_{37}$ Véase otros ejemplos en Librán y Sanz 2019, pp. 215, 217, 219.

${ }^{38}$ Librán 2019, pp. 298, 301.

39 Gärtner 2010, pp. 259-260.

${ }^{40}$ Librán 2019, p. 301 (cf. Parth. X 4).

${ }^{41}$ Stramaglia 2001, p. 92; Brioso 2007, p. 265; Gärtner 2010, pp. 259-260.

${ }^{42}$ Stramaglia 1992, p. 59; Gärtner 2010, p. 262; Braccini 2015, p. xiii; Librán 2019, p. 305.

${ }^{43}$ Crespo 1982, p. 391. 
hecha a base de reptiles venenosos ${ }^{44}$. A su vez, las abejas que han elaborado dicha miel ahuyentan con sus aguijones a los soldados que se acercan a su colmena, lo que permite a la pareja protagonista escapar de la caverna y eludir a sus perseguidores ${ }^{45}$. Así, el hipotexto historiográfico aportaría realismo y racionalismo al carácter fantástico que caracteriza al cuento de hadas ${ }^{46}$. Encontramos un caso parecido de racionalización de un suceso aparentemente sobrenatural en otro episodio de la novela: la desgracia de Tigris, fallecido por comer una rosa (Phot., Bibl. XCIV 9). En realidad, en el corazón de la flor se escondía un insecto venenoso (Phot., Bibl. XCIV 9, 11): una cantárida (Lytta vesicatoria), coleóptero sumamente tóxico que anidaba (entre otros sitios) en las rosas blancas y segregaba una sustancia letal si se ingería (Plin., Nat. XXIX 30.93-94). Tigris falleció realmente al deglutir la cantárida, como ocurrió en la vida real, por ejemplo, con un tal Cosino, un équite amigo de Nerón, muerto tras beber una poción con polvo hecho de este insecto (Plin., Nat. XXIX 30.93).

(b) Un segundo objetivo de dicha combinación de modelos literarios puede ser el de motivar el ajuste del relato al esquema narrativo que se repite en la primera parte de Babiloníacas ${ }^{47}$ : cada episodio de esta primera parte se caracteriza por el hecho de que la pareja protagonista se libra por poco de la muerte, mientras que otros personajes secundarios a su alrededor fallecen ${ }^{48}$. Cada escena de escape de la muerte representa la misma situación básica, si

${ }^{44}$ Schneider-Menzel 1948, p. 88. La intoxicación e incluso muerte por ingestión de miel tóxica era y sigue siendo una realidad en el Cáucaso y la actual Turquía. Véase e. g. Mayor 1995, pp. 33-34. Sobre la repetición del tópico novelístico de la falsa muerte en Babiloníacas véase Holzberg 1986, p. 86; Brioso 2008; pp. 251-252; Sevieri 2017, p. 67.

${ }^{45}$ Sevieri 2017, p. 12, 68. Es esta una observación perfectamente realista: las picaduras simultáneas de muchas abejas pueden matar a un ser humano (Moore y Kosut 2013, p. 32). Sobre el uso en la antigüedad de abejas y avispas como armas biológicas véase Moore y Kosut 2013, p. 33.

${ }^{46}$ Quizá sea relevante, al respecto de la influencia de la historiografía en Babiloníacas, que Focio aparentemente veía relación entre Babiloníacas y obras historiográficas como las de Arriano (Connors 2018, pp. 48-49).

${ }^{47}$ Babiloníacas está estructurada en tres partes bien diferenciadas (véase e. g. Crespo 1982, pp. 392-393). Uno de los revisores anónimos de Emerita precisa que este tipo de episodios, estructurados según la pareja de funciones peligro-auxilio, es característico de la novela griega de amor. Véase al respecto Ruiz Montero 1987, pp. 35-40.

${ }^{48}$ Stephens y Winkler 1995, pp. 185-186. 
bien con variaciones en el tono emocional y en la lista de personajes. Ninguno de estos episodios es prescindible, ya que cada repetición del esqueleto narrativo aporta alguna circunstancia o elemento nuevo que desempeñará posteriormente un papel importante en la narración ${ }^{49}$. En el caso del episodio de las abejas, ocurre de esta misma manera: tras la carnicería de las abejas contra los soldados, Ródanes y Sinónide se despiertan del coma inducido por la ingestión de la miel tóxica, recogen las ofrendas fúnebres (ropas y alimentos) que han dejado a su alrededor los soldados de Damas, quienes los habían dado por muertos, y huyen cargados con ellos en dirección contraria (Phot., Bibl. XCIV 4). Posteriormente, Sinónide trata de vender unos mantos $(i \mu \alpha ́ \tau 1 \alpha)^{50}$ y es aprehendida como saqueadora de tumbas, por lo que es llevada ante Soreco. Este encuentro le granjea a Sinónide la oportunidad de conocer a uno de los personajes cruciales de la novela, que actuará como su protector y salvador (Phot., Bibl. XCIV 7): sin el encuentro con las abejas y su miel, Ródanes y Sinónide no habrían podido escapar de la persecución de los soldados de Damas ni habrían conocido a Soreco; además, tampoco habrían tenido medios ni recursos para subsistir hasta entonces ${ }^{51}$.

En cuanto a la repetición del esquema narrativo mencionado supra, curiosamente la secuencia del encuentro con un insecto venenoso y una planta que resultan letales para un personaje secundario, de lo que acaba beneficiándose la pareja protagonista, reaparece en el episodio ya mencionado de la muerte de Tigris $^{52}$ : el fallecimiento del joven tras comer una rosa cuyo interior escondía una cantárida propicia la confusión de identidades entre Tigris, Éufrates y Ródanes que motiva la acción de la última parte de la novela (Phot., Bibl. XCIV 11-12, 20).

Por otra parte, Jámblico emplea nexos de unión para vincular orgánicamente los distintos modelos que maneja para sus fines literarios: a modo de ejemplo, en el caso ya citado del episodio del perro hircano de Ródanes (Phot., Bibl. XCIV 18), es el propio animal el que sirve como vehículo para

${ }^{49}$ Stephens y Winkler 1995, p. 186.

${ }^{50}$ Estos mantos proceden verosímilmente tanto de los dones fúnebres tributados por

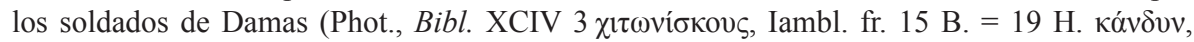
$\chi \lambda \alpha \mu v \delta \delta \alpha)$ como de las ofrendas funerarias $(\pi \varepsilon ́ \pi \lambda \omega v)$ que Ródanes y Sinónide han tomado de la tumba vacía de la joven resucitada (Phot., Bibl. XCIV 6).

${ }^{51}$ Sevieri 2017, p. 69.

52 Connors 2018, p. 47. 
combinar las alusiones literarias que actúan en esta aventura: Cianipo y Leucónoe, Píramo y Tisbe (en el mismo papel que la leona de esta narración) y Erígona y la perra $\mathrm{Mera}^{53}$. En el episodio de las abejas, el vínculo entre los dos modelos literarios planteados (Jenofonte y el cuento popular reflejado en Eliano, Antonino Liberal y Conón) que permite una conjunción fluida de ambos es la presencia de las abejas y la miel en uno y otro caso: el papel de los soldados de Jenofonte, los que experimentan el envenenamiento por miel tóxica, se transfiere a los fugitivos (la pareja protagonista, Ródanes y Sinónide), mientras que el motivo de la derrota tras la guerra de las abejas se traslada de los ladrones o los fugitivos a los soldados de Damas.

Todo ello sirve para confirmar con ejemplos la observación de Focio (Bibl. XCIV 1) sobre la habilidad de Jámblico para armar la arquitectura literaria de Babiloníacas:

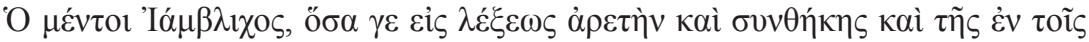

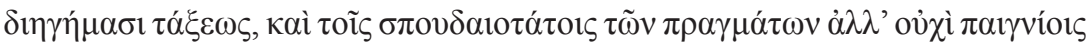

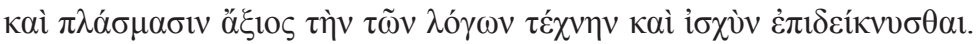

Jámblico, al menos en lo que toca a la calidad de su dicción, la estructura y la arquitectura de su narración, habría merecido demostrar la técnica y el vigor de su narrativa con argumentos más serios, no con juegos y con invenciones.

\section{Conclusiones}

El propósito del presente artículo era doble: la búsqueda de los modelos literarios que ayudaron a inspirar el episodio de las abejas en Babiloniacas de Jámblico (Phot., Bibl. XCIV 3-4) y el propósito literario que cumplía su uso y adaptación.

En cuanto al primer objetivo, sugiero que se pueden detectar dos modelos distintos: por un lado, un texto historiográfico (X., An. IV 8.20-21), que narra el envenenamiento de los compañeros de Jenofonte por culpa de una miel tóxica, y un cuento popular del que han quedado restos de forma independiente en Ant. Lib. XIX 1-3, Cono XXXV y Ael., NA XVII 45, el cual relata el ataque de unas abejas sagradas que tienen su colmena en una caverna contra quienes se llevan su miel. Ambos elementos se documentan en el epi-

\footnotetext{
${ }^{53}$ Gärtner 2010, p. 261.
} 
sodio de las abejas de Babiloníacas, a saber: la ingestión de miel tóxica y la muerte aparente experimentada de resultas de ello por Ródanes y Sinónide, y la guerra de las abejas contra los soldados que estaban persiguiendo a la pareja protagonista horadando la cueva.

En cuanto al segundo objetivo, se comprueba una vez más la tendencia de Jámblico, ya observada por otros estudiosos, a mezclar modelos y alusiones literarios y adaptarlos a sus fines creativos. En este caso, la combinación de modelos, uno historiográfico y el otro procedente del cuento popular, ayuda tanto a motivar de forma racionalizante la aparición de los elementos maravillosos de la narración como a ajustar el episodio a la estructura narrativa principal de la primera parte de la novela.

Todo ello sirve para cimentar la impresión, ya apuntada por el propio Focio, de la habilidad y capacidad de Jámblico como narrador.

\section{BiBLIOGRAFÍA}

Anderson, G. (2000): Fairytale in the Ancient World, Londres-Nueva York.

Anderson, G. (2004): King Arthur in Antiquity, Londres-Nueva York.

Barbero, M. (2015): I Babyloniaca di Giamblico, Alejandría.

Beck, R. (1982): «Soteriology, the Mysteries, and the Ancient Novel: Iamblichus' Babyloniaca as a Test-Case», en Bianchi, U. y Vermaseren, M. J. (eds.), La soteriologia dei culti orientali nell'imperio Romano, Leiden, pp. 527-540.

Bianchi, N. y Schiano, C. (2016): Fozio. Biblioteca, introduzione di L. Canfora, a cura di N. Bianchi e C. Schiano, nota sulla tradizione manoscritta di S. Micunco, Pisa.

Borgogno, A. (1975): «Sui Babyloniaca di Giamblico», Hermes 103, pp. 101-126.

Bowie, E. (2017): «Xenophon's Influence in Imperial Greece», en Flower, M. A. (ed.), The Cambridge Companion to Xenophon, Cambridge, pp. 403-415.

Braccini, T. (2015): «Le Storie babilonesi di Giamblico: una premessa», en Barbero, M., I Babyloniaca di Giamblico, Alejandría, pp. VII-XXIV.

Brioso, M. (2007): «El motivo de la muerte aparente en la novela griega antigua (I)», Habis 38, pp. 249-270.

Brioso, M. (2008): «El motivo de la muerte aparente en la novela griega antigua (II)», Habis 39, pp. 245-266.

Brown, M. K. (2002): The Narratives of Konon. Text, Translation and Commentary of the Diegeseis, Leipzig.

Celoria, F. (1992): The Metamorphoses of Antoninus Liberalis: a Translation with a Commentary, Londres-Nueva York. 
Connors, C. (2018): «Babylonian Stories and the Ancient Novel: Magi and the Limits of Empire in Iamblichus' Babyloniaka», en Pinheiro, M. P. F., Konstan, D. y MacQueen, B. D. (eds.), Cultural Crossroads in the Ancient Novel, BerlínBoston, pp. 39-50.

Cook, A. B. (1895): «The Bee in Greek Mythology», JHS 15, pp. 1-24.

Crespo, E. (1982): Jámblico, Babiloníacas (resumen de Focio y fragmentos) en Brioso, M. y Crespo, E., Longo, Dafnis y Cloe; Aquiles Tacio, Leucipa y Clitofonte; Jámblico, Babiloníacas (resumen de Focio y fragmentos), Madrid.

Di Gregorio, L. (1963): «Su alcuni frammenti delle Storie Babilonesi di Giamblico», Aevum 37, pp. 390-405.

Dowden, K. (2018): «The Plot of Iamblichos' Babyloniaka: Sources and Influence», en Chew, M., Morgan, J.R. y Trzaskoma, S. M. (eds.), Literary Currents and Romantic Forms: Essays in Memory of Bryan Reardon, Groninga, pp. 149-72.

Gärtner, T. (2010): «Literarische Anspielungen in den Babyloniaka des Iamblichos», Prometheus 36 (3), pp. 258-262.

Habrich, E. (1960): Iamblichi Babyloniacorum reliquiae, Leipzig.

Hansen, W. (2002): Ariadne's Thread. A Guide to International Tales Found in Classical Literature, Ithaca-Londres.

Holzberg, N. (1986): The Ancient Novel. An Introduction, Londres-Nueva York.

Kanavou, N. (2019): «Iamblichos’ Babyloniaka, the Greek Novel and Satire», Ancient Narrative 15, pp. 109-131.

Kroll, W. (1914): «Iamblichos 2», RE 9 (1), coll. 640-645.

Lamer, H. (1924): «Laios 2», RE 12 (1), coll. 512-513.

Librán, M. (2019): «Motivos de cuentos populares en Babiloníacas de Jámblico», Liburna 14, pp. 291-306.

Librán, M. y Sanz, M. (2019): «Animales y cuento popular en Jámblico, Babiloníacas», Prometheus 45, pp. 205-222.

Mayor, A. (1995): «Mad Honey!», Archaeology 48.6, pp. 32-40.

Mitchell, A. G. (2009): Greek Vase-Painting and the Origins of Visual Humour, Cambridge-Nueva York.

Moore, L. J. y Kosut, M. (2013): «Bees, Border and Bombs: A Social Account of Theorizing and Weaponizing Bees», en Hediger, R. (ed.), Animals and War: Studies of Europe and North America, Leiden-Boston, pp. 29-43.

Naechster, M. (1908): De Pollucis et Phrynichi controversiis, Leipzig.

Papathomopoulos, M. (1968): Antoninus Liberalis: Les Métamorphoses, París.

Rohde, E. (1876): Der griechische Roman und seine Vorlaüfer, Leipzig.

Rojas, L. (2016): «Las Babiloníacas de Jámblico. Una novela erótica sui generis», Nova Tellus 34 (2), pp. 39-52.

Ruiz Montero, C. (1987): La novela griega. Análisis funcional, Salamanca.

Ruiz Montero, C. (2006): La novela griega, Madrid. 
Sanz Morales, M. (2020): «Sobre las fuentes de Jámblico, Babiloniacas, fr. 1 Habrich

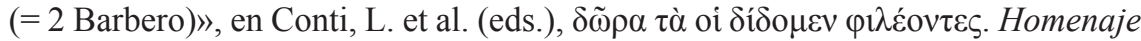
al profesor Emilio Crespo, Madrid, pp. 509-516.

Schneider-Menzel, U. (1948): «Jamblichos’ Babylonische Geschichten», en Altheim, F. (ed.), Literatur und Gesellschaft im ausgehenden Altertum, vol. I, Halle, pp. 48-92.

Sevieri, R. (2017): Giamblico. Storie babilonesi, Milán.

Stephens, S. y Winkler, J. J. (1995): Ancient Greek Novels. The Fragments, Introduction, Text, Translation and Commentary, Princeton.

Stramaglia, A. (1992): «Il leone, il tesoro e l'indovinello: IG IV ${ }^{2}$ 1, 123, 8-21 e Giamblico, Storie babilonesi 3 e 21 Habr.», ZPE 91, pp. 53-59.

Stramaglia, A. (2001): «Piramo e Tisbe prima di Ovidio? PMich inv. 3793 e la narrativa d'intrattenimento alla fine dell'età tolemaica», ZPE 134, pp. 81-106.

Thompson, S. (1955-1958): Motif-Index of Folk-Literature: a Classification of Narrative Elements in Folktales, Ballads, Myths, Fables, Medieval Romances, Exempla, Fabliaux, Jest-Books, and Local Legends. Revised and enlarged edition, Bloomington.

Wilson, N. (1992): Fozio. Biblioteca, Milán.

Fecha de recepción de la primera versión del artículo: 04/05/2020

Fecha de aceptación: 17/06/2020

Fecha de recepción de la versión definitiva: 27/06/2020 
